\title{
Boiler Level Control Using Labview
}

\author{
B. Hemalatha \\ SRM UNIVERSITY \\ Kattankulathur-603203
}

\author{
Dr. A.Vimala Juliet \\ SRM UNIVERSITY \\ Kattankulathur-603203
}

\author{
N.Natarajan \\ SRM UNIVERSITY \\ Kattankulathur-603203
}

\begin{abstract}
A boiler system is an integral component of a sugar plant and control of water level in the drum of the boiler is a critical operational consideration. Nowadays, instead of conventional control techniques, modern control techniques have been implemented for a lot of industrial models practically or theoretically. In this paper, we describe the effectiveness of LabVIEW in order to provide better drum level control of various products evolved in a sugarcane industry.
\end{abstract}

\section{General Terms}

Theory ,Algorithms, mathematical modeling, Characteristics, Performance, Design, Control basis, Reliability, Experimentation, LabVIEW environment, Human Factors, Theory, Legal Aspects, Verification.

\section{Keywords}

LabVIEW, State-space analysis, DCS embedded LabVIEW.

\section{INTRODUCTION}

The dynamic behavior of industrial plants heavily depends on disturbances and in particular on changes in operating point. The main input variables of a sugarcane plant are fuel, feedwater and air. The outputs of the system are electrical power, steam pressure, steam temperature, flue gas as shown in Figure 1.

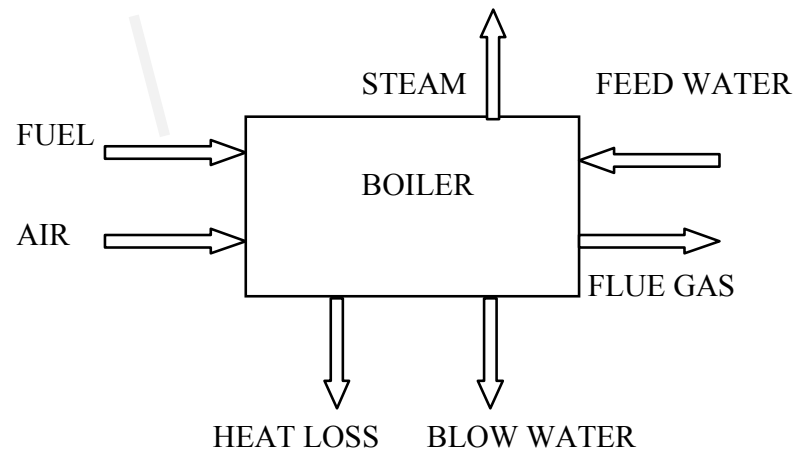

Fig.1.Basic elements of Boiler

Some of the inputs and outputs are more important than the others since these are adequate for modeling the plant. These are fuel feed and feedwater flow as the inputs, and the electrical power and steam enthalpy as the outputs [1]. The conventional systems today at Sugarcane industries are operated using PLCs and DCS which requires professionalism with higher technical abilities so as to operate the same. LabVIEW has been emerging onto each and every field evolving broader scope of improvement at every level. The graphical user interface is a key factor which simplifies the scope of learning compared to the above mentioned. In addition, the training period required is of short duration compared to PLCs and DCS. LabVIEW also increases the comfort levels of the persons working at the plant and acts as a substitute for the DCS system installed in the control room. Keeping this view in mind this paper is being put up in order to improvise on the level control in the boiler, efficiency and quality of the product obtained with the maximum utilization of the available resources so that the transition would provide better stand-alone system, a cut above the existing technologies. The simulation results show that the PID [4] controller developed in this study performs better than the rest controllers on the settling time and overshoot of power and enthalpy outputs.

\section{VIRTUAL INSTRUMENTATION}

Standard virtual instrumentation [3] software is structure effectively to perform both user -end and process /machine level tasks. The user process takes care of all the front-end functions that graphical programs can be developed, modified and redeployed to absorb maximum human flexibility as required in a teaching or training environment. The graphical software creates virtual instruments (VIs) developing block-diagrams using nodes, terminals and wires. With the icon/connector, a VI can be used as a Sub VI in the block diagram of another VI. All advanced programming techniques with add-on tools and libraries can be graphically represented with minimum amount of coding-hours in this environment. The web interface and interactivity in the deployed VI modules has used Control Design and Simulation module linked to LabVIEW.

\section{PROCESS}
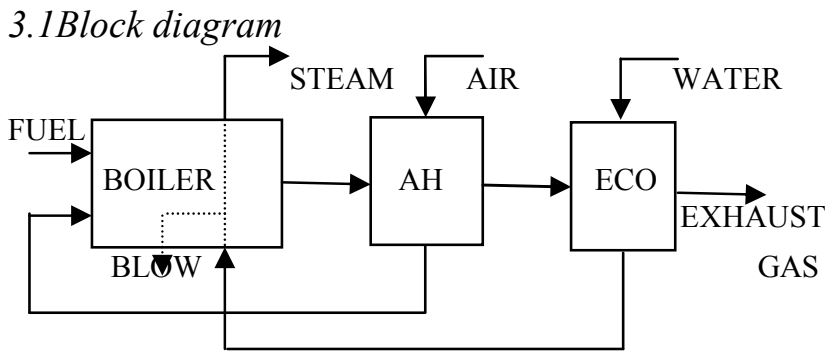

Fig.2.Block diagram representation of Boiler

Super heater coils is the highest temperature point used in a boiler to generate saturated steam and also removes the moisture content present in the steam when temperature increases. Water wall tubes 
are the steam generating tubes where the water gets evaporated into steam. Deaerators are used to remove oxygen content present in feed water which causes erosion and corrosion. Economizer is a heat recovery unit used in downstream of boiler bank to preheat the feed water absorbing heat from the hot exhaust gas.

\subsection{MODELING}

The most important aspect of any system is the theoretical analysis, which is a key for the prediction of the system being developed. Keeping this in mind the boiler equations were formulated and toolkits like Control, design and Simulation were used in order to study the dependencies of the input variables to the output variables. LabVIEW platform provides ease of analysis at your desktop. The mathematical equation for the analysis of the tube boiler type has been provided as follows:

\subsubsection{Mathematical equations}

Mass balance equation for the steam in the drum :

$\mathrm{d} / \mathrm{dt}\left(\ell_{\mathrm{s}} \cdot \mathrm{V}_{\mathrm{s}}\right)=\mathrm{X}_{\mathrm{r}} \cdot \mathrm{q}-\mathrm{q}_{\mathrm{s}}$

Mass balance equation for the water in the system:

$\mathrm{d} / \mathrm{dt}\left(\ell_{\mathrm{w}} \cdot \mathrm{V}_{\mathrm{w})}=\mathrm{q}_{\mathrm{fw}}-\mathrm{q}_{\mathrm{s}}\right.$

Mass balance equation for the steam in the risers:

$\mathrm{d} / \mathrm{dt}\left(\ell_{\mathrm{s}} \cdot \mathrm{a} \cdot \mathrm{V}_{\mathrm{r}}\right)=\mathrm{P} / \mathrm{hc}-\mathrm{X}_{\mathrm{r}} \cdot \mathrm{q}$

The circulation flow $\mathrm{q}$ is given by the momentum balance:

$$
\left(\ell_{\mathrm{w}}-\ell_{\mathrm{s}}\right)=\mathrm{k} \cdot \mathrm{q}^{2}
$$

where

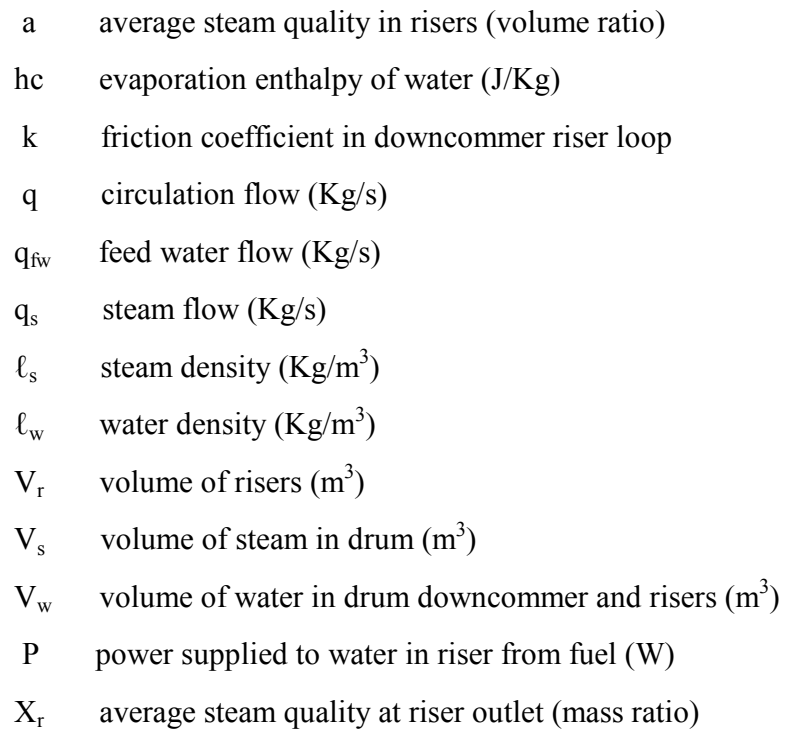

\subsubsection{Representation of system}

The state space equation for the above mathematical model is given by:
The inputs are $\mathrm{P}, \mathrm{q}_{\mathrm{fw}}$ and $\mathrm{q}_{\mathrm{s}}$.

The state variables are $\ell_{\mathrm{s}}, \mathrm{V}_{\mathrm{w}}$ and a.

The outputs of the system are $\ell_{\mathrm{s}}, \mathrm{dl}$ and a.

$$
\begin{aligned}
& \frac{\mathrm{d}}{\mathrm{dt}}\left[\begin{array}{l}
\delta \rho_{s} \\
\delta \mathrm{V}_{v} \\
\delta \mathrm{a}
\end{array}\right]=\left[\begin{array}{crr}
\mathrm{A} 11 & 0 & 0 \\
0 & 0 & 0 \\
\mathrm{~A} 31 & 0 & \mathrm{~A} 33
\end{array}\right]\left[\begin{array}{l}
\delta \rho_{s} \\
\delta \mathrm{V}_{v} \\
\delta \mathrm{a}
\end{array}\right]+\left[\begin{array}{lll}
\mathrm{B} 11 & \mathrm{~B} 12 & \mathrm{~B} 13 \\
0 & \mathrm{~B} 22 & \mathrm{~B} 23 \\
\mathrm{~B} 31 & \mathrm{~B} 32 & \mathrm{~B} 33
\end{array}\right]\left[\begin{array}{l}
\delta \mathrm{P} \\
\delta \mathrm{q}_{\mathrm{v}} \\
\delta \mathrm{q}_{\mathrm{s}}
\end{array}\right] \\
& {\left[\begin{array}{c}
\delta \rho_{\mathrm{a}} \\
\delta \mathrm{d} 1 \\
\delta \mathrm{a}
\end{array}\right]=\left[\begin{array}{ccc}
1 & 0 & 0 \\
0 & \mathrm{C} 22 & \mathrm{C} 23 \\
0 & 0 & 1
\end{array}\right]\left[\begin{array}{l}
\delta \rho_{\mathrm{s}} \\
\delta \mathrm{v} \\
\delta \mathrm{a}
\end{array}\right]}
\end{aligned}
$$

where $\delta$ denotes derivation from the equilibrium

$\delta \rho_{s}=\rho_{s}-\rho_{s}^{0}$

$\mathrm{A} 11=-\frac{\mathrm{q}_{\mathrm{fv}}}{\mathrm{hc}} \frac{o \mathrm{hc}}{o \rho_{\mathrm{s}}}$

$\mathrm{A} 31=-\frac{\mathrm{q}_{\mathrm{tv}}}{\rho_{\mathrm{s}} \mathrm{b} \mathrm{V}_{\mathrm{r}} \mathrm{hc}} \frac{o \mathrm{hc}}{o \rho_{\mathrm{s}}}-\frac{\mathrm{q}_{\mathrm{r}}}{\mathrm{q}_{\mathrm{g}}{ }^{2} \mathrm{~V}_{\mathrm{r}}} \frac{\rho_{v}-1.5 \mathrm{q},}{\rho_{\mathrm{v}}-\rho_{\mathrm{g}}}$

$\mathrm{A} 33=-\frac{2 \mathrm{q}}{\rho_{\text {. }} \mathrm{V}_{\mathrm{r}}}$

$B 11=\frac{1}{h c\left(V_{s}+a V_{r}\right)}$

$$
\begin{aligned}
& B 12=\frac{\rho_{a}}{\rho_{v}\left(V_{n}+a V_{r}\right)} \\
& \mathrm{B} 13=-\frac{1+\rho_{0} / \rho_{v}}{V_{s}+a V_{r}} \\
& \mathrm{~B} 22=1 / \rho_{\text {. }} \\
& \mathrm{B} 23=-1 / \rho_{v} \\
& \text { B31 }=\frac{1}{h c \rho_{g} V_{r}\left(1+a V_{r} / V_{q}\right)} \\
& \mathrm{B} 32=\frac{\mathrm{a}}{\rho_{\mathrm{v}}\left(\mathrm{V}_{\mathrm{o}}+\mathrm{a} \mathrm{V}_{\mathrm{r}}\right)} \\
& \text { B33 }-\frac{a\left(\rho_{v}+\rho_{\mathrm{a}}\right)}{\rho_{\mathrm{s}} \rho_{\mathrm{v}}\left(\mathrm{V}_{\mathrm{s}}+\mathrm{a} \mathrm{V}_{\mathrm{r}}\right)}
\end{aligned}
$$

\subsubsection{Graph}

The response of the above system is shown in figure below: 


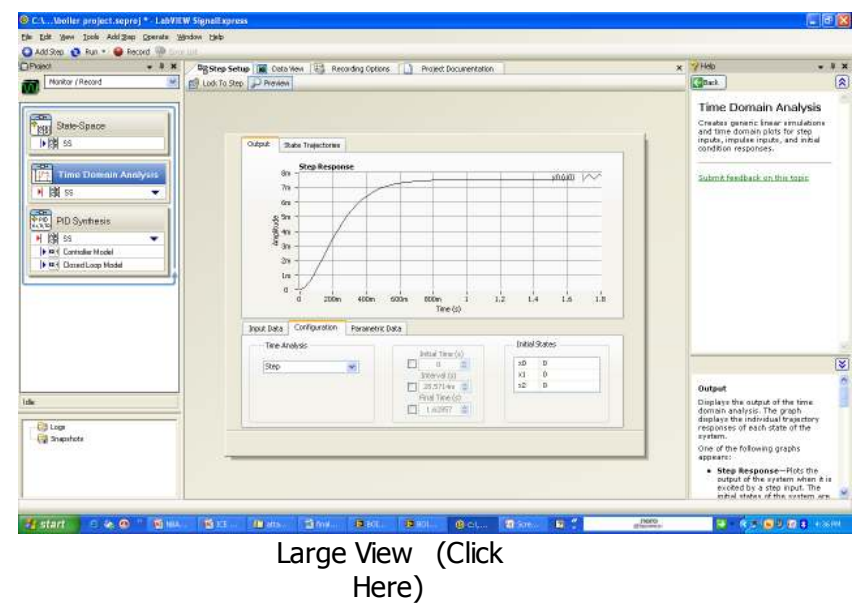

Fig.3.The response of the system in LabVIEW signal Express.

The above graph (see fig.3) illustrates the stability of a single output (level) of the boiler. As shown in figure the system attains stability after 1 second of the activation of the system. This is with reference to the theoretical calculations of the system shown above.

\subsection{CHARACTERISTICS OF CURVE}

\subsubsection{PID Response}

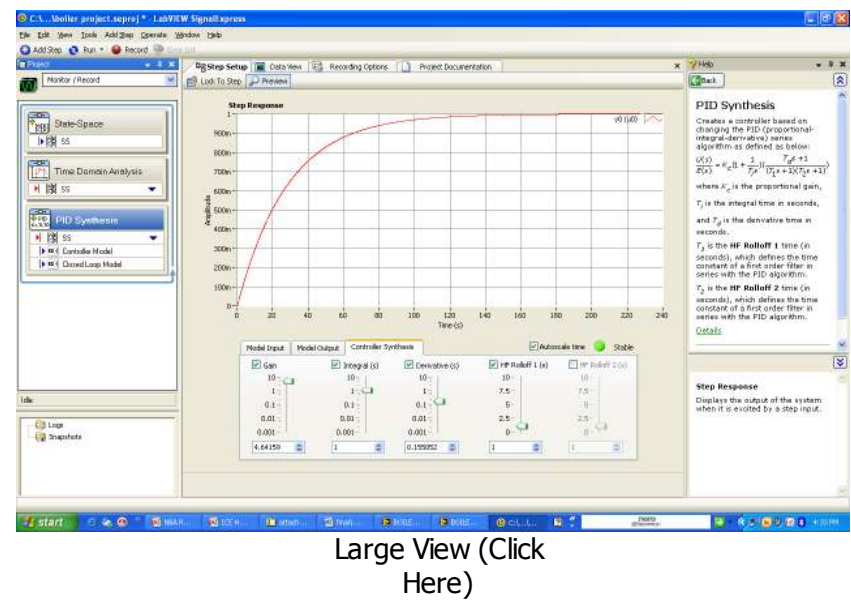

Fig.4. PID response of the system using LabVIEW signal Express.

The above diagram (see fig.4) illustrates the PID response of the system and tuning of the controller parameters for attaining the stability of the system under test. The green light in the figure indicates that the system is stable under chosen closed loop function.

\subsubsection{Inferences}

There are quite a few remarks based on the study of the graph and its analysis:

(i). The gain of the system has been assumed to be unity. (ii). The integral parameter was found to be 1.7302 .

(iii). The derivative parameter was found to be 0.0013895 .

\subsection{CONTROL ALGORITHM}

\subsubsection{General System dependencies}

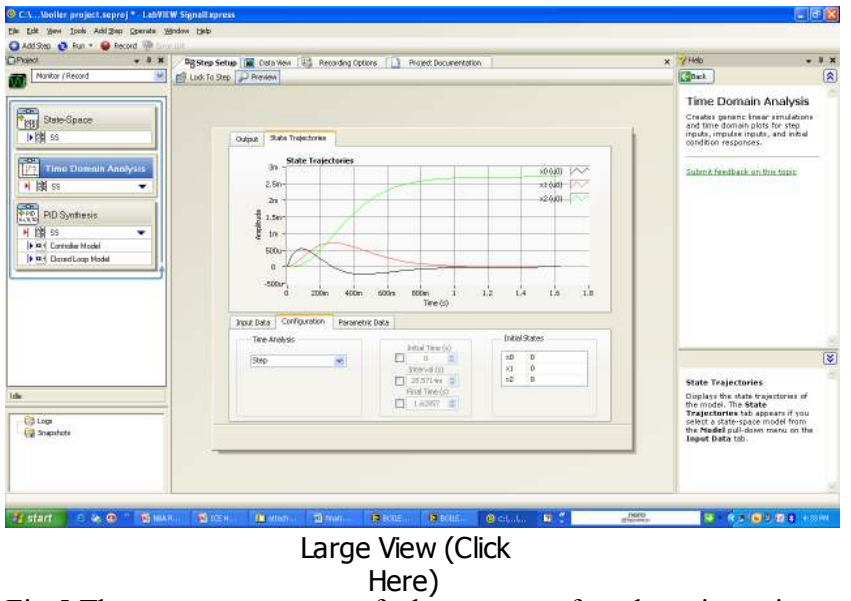

Fig.5.The state response of the system for the given input parameters.

A state space representation is a mathematical model of a physical system as a set of input, output and state variables related by firstorder differential equations. To abstract from the number of inputs, outputs and states, the variables are expressed as vectors and the differential and algebraic equations are written in matrix form (the last one can be done when the dynamical system is linear and time invariant). The state space representation (also known as the "time-domain approach") provides a convenient and compact way to model and analyze systems with multiple inputs and outputs. Unlike the frequency domain approach, the use of the state space representation is not limited to systems with linear components and zero initial conditions. "State space" refers to the space whose axes are the state variables.

\subsubsection{Our approach}

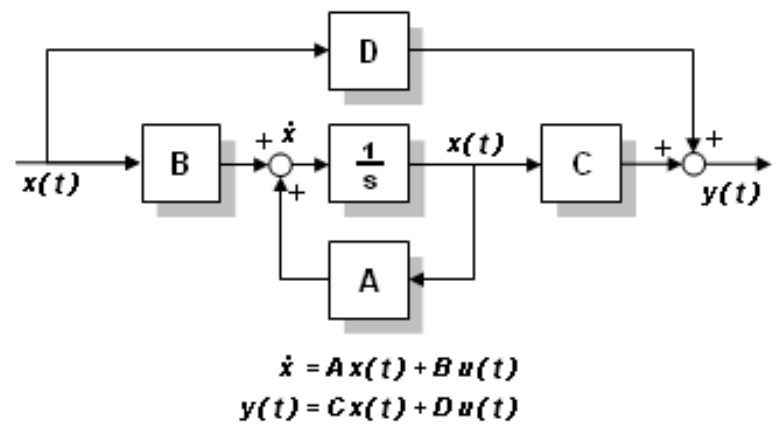

Fig.6.A closed loop block diagram representing the system designed.

\subsubsection{Reliability}

This system ensures higher accuracy compared to the conventional systems that are existing in the sugarcane industry. In addition, this system can minimize the error of liquid level 
measurement up to $2 \%$ compared to $5 \%$ error approximation being carried out in today's scenario. It also takes care of the efficiency of the boiler and the variables being controlled. The LabVIEW based real-time control algorithm provides flexibility and endurance to survive in this competing world.

\subsubsection{LabVIEW Workbench}

\subsubsection{Front panel}

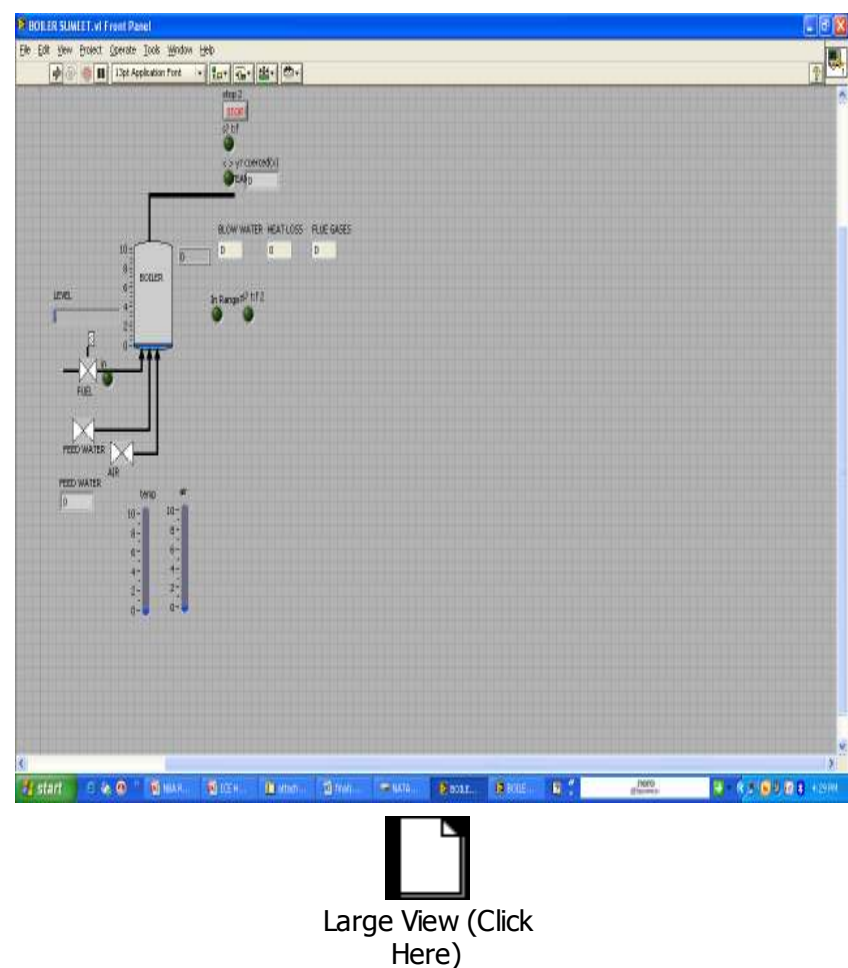

Fig.7.The diagram illustrating the front panel of the vi.Block Diagram

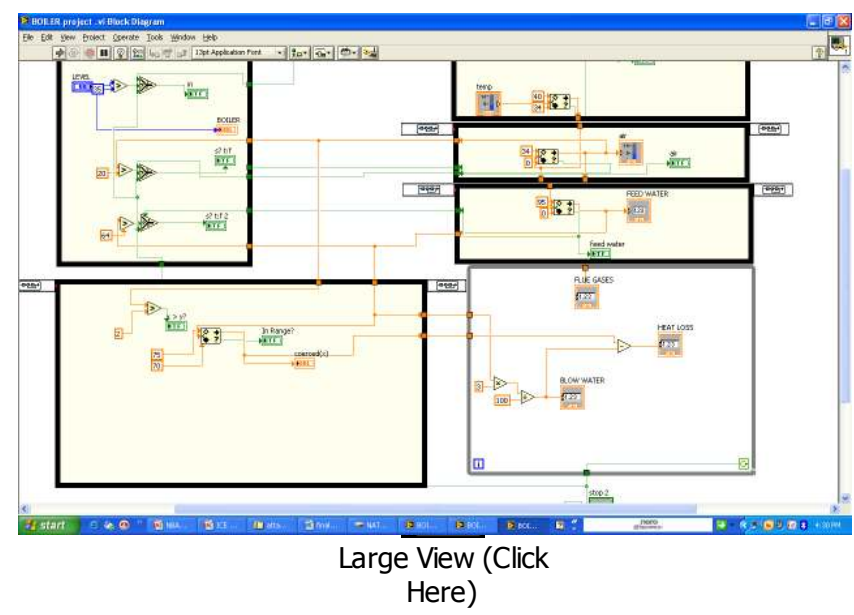

Fig.7.A screenshot of the block diagram of the vi.

\section{CONCLUSION}

The level of the drum is being controlled using LabVIEW. The output variables have been accorded in relation with the boiler parameters. This project can be further applied for a real-time boiler application as well.

\section{REFERENCES}

[1] Unbehauen, H., Kocaarslan, I., Experimental Modelling and Adaptive Power Control of a $750 \mathrm{MW}$ Once-Through Boiler, Proceedings of 11th IFAC World Congress, Tallin, SU, Vol. 4, pp. 226-23,11317 August 1990.

[2] Eun Gen Kim, 1990.Control system Design of boiler drum level. In Proceedings of ISL Winter Workshop, Vol. 3,February 7-9,1990.(C) ISL .

[3] Amit Chaudhuri ,Amitava Akuli, Abhijit Auddy .2002.Virtual Instrumentation Systems-some developments in power plant training and education. IEEE ACE 2002, December 20-21,2002, organized by IEEE Calcutta.

[4] National Instruments, Control Theory and PID Theory. www.ni.com/ezone.

[5] Tavel, P. 2007 Modeling and Simulation Design. AK Peters Ltd.

[6] The Control Of Boilers SAM G. DUKELOW 